\title{
Numerical and experimental investigation of leaks in viscoelastic pressurized pipe flow
}

\author{
S. Meniconi, B. Brunone, M. Ferrante, and C. Massari \\ Dipartimento di Ingegneria Civile ed Ambientale, Università degli Studi di Perugia, Perugia, Italy \\ Correspondence to: S. Meniconi (silvia.meniconi@unipg.it) and B. Brunone (brunone@unipg.it) \\ Received: 27 July 2012 - Published in Drink. Water Eng. Sci. Discuss.: 3 September 2012 \\ Revised: 11 January 2013 - Accepted: 28 January 2013 - Published: 8 February 2013
}

\begin{abstract}
This paper extends the analysis concerning the importance in numerical models of unsteady friction and viscoelasticity to transients in plastic pipes with an external flow due to a leak. In fact recently such a benchmarking analysis has been executed for the cases of a constant diameter pipe (Duan et al., 2010), a pipe with a partially closed in-line valve (Meniconi et al., 2012a), and a pipe with cross-section changes in series (Meniconi et al., 2012b). Tests are based on laboratory experiments carried out at the Water Engineering Laboratory (WEL) of the University of Perugia, Italy, and the use of different numerical models. The results show that it is crucial to take into account the viscoelasticity to simulate the main characteristics of the examined transients.
\end{abstract}

\section{Introduction}

If the transients in a pressurized constant diameter pipe supplied by a constant head reservoir - hereafter referred to as single pipe - due to the instantaneous closure of a valve placed at the downstream end section, are simulated by means of the Allievi-Joukowsky analytical model (Fig. 1a, continuous line), no decay of the pressure peaks takes place after the end of the manoeuvre. In fact, in this case friction effects are neglected and an elastic behaviour of the pipe material is assumed. In Fig. 1, the time-history of the dimensionless piezometric head - hereafter referred to as dimensionless pressure signal - at the end section of the pipe, $h=\left(H-H_{0}\right) / \Delta H_{\mathrm{AJ}}$ is shown, where $H=$ piezometric head, $\Delta H_{\mathrm{AJ}}=a_{\mathrm{i}} Q_{0} /(\mathrm{Ag})$ is the Allievi-Joukowsky overpressure, $a_{\mathrm{i}}=$ instantaneous elastic pressure wave speed, $Q=$ discharge, $A=$ pipe area, $g=$ acceleration gravity, $\theta=t / \tau$ is the dimensionless time with $t=$ time evaluated from the beginning of manoeuvre, $\tau=2 L / a$ is the characteristic time of the pipe, $L=$ pipe length, $a=$ mean pressure wave speed, and the subscript 0 refers quantities to the initial conditions.

When friction forces in an elastic pipe are evaluated by means of the uniform flow formulas, i.e. within the so called steady-state approach (Fig. 1a, dashed line almost undistinguishable from the continuous line), no valuable differ- ence occurs with respect to the Allievi-Joukowsky model in terms of decay and rounding of pressure peaks. Thus nor the Allievi-Joukowsky model nor the one based on the steady-state approach, simulate properly the strong decay and rounding of pressure peaks of experimental data both in elastic (Fig. 1b) and viscoelastic (Fig. 1c) pipes. This result has motivated the intense research activity in the field of unsteady friction (Adamkowski and Lewandowski, 2006; Bergant et al., 2001; Brunone et al., 1991, 1995; Brunone and Berni, 2010; Ghidaoui et al., 2005; Pezzinga, 2000, 2009; Storli and Nielsen, 2011; Zielke, 1968) and viscoelasticity (Covas et al., 2004, 2005; Ferrante et al., 2011; Franke and Seyler, 1983; Ghilardi and Paoletti, 1986; Meniconi et al., 2012a, b; Soares et al., 2008) modelling during transients in pressurized pipes in the last two decades. In fact the damping and rounding of pressure peaks in a single pipe are ascribed to the effect of unsteady friction in elastic pipes and to both unsteady friction and viscoelasticity in plastic ones. Only recently, Duan et al. (2010) have shown quantitatively that in plastic pipes the role of unsteady friction is relevant only in the first phases of the transients. In other words, the viscoelastic effect becomes more and more dominant with respect to unsteady friction, as time progresses. 

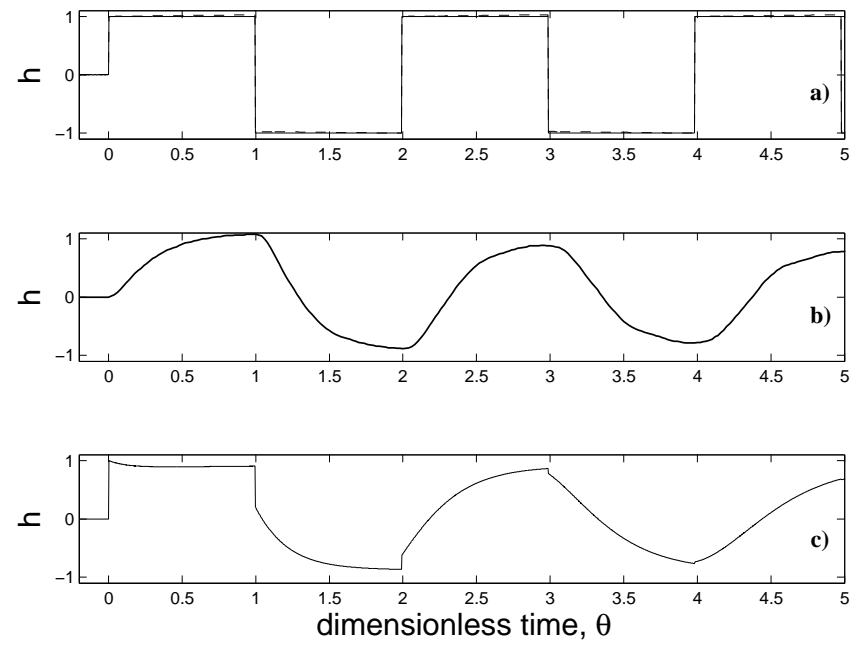

Figure 1. Dimensionless pressure signal in a single pipe due to the instantaneous closure of the end valve: (a) continuous line: Allievi-Joukowsky model (frictionless and elastic pipe) and dashed line: steady-state approach (steady-state friction and elastic pipe), (b) typical experimental data in elastic pipes, and (c) typical experimental data in viscoelastic pipes.

The interest in the simulation of transients in pressurized pipes is not due only to the importance of evaluating properly the extreme values of the pressure. In fact in the last two decades, starting from the pioneering paper by Liggett and Chen (1994), transient test-based techniques for leak detection and sizing have been more and more used because of their reliability and cheapness (Colombo et al., 2009). Within such techniques several distinctions can be made about the role played in the diagnosis procedure by the equations governing transients. Precisely, to locate and size leaks, the momentum and continuity equations can be solved and the numerical results are compared with the experimental data; alternatively, only the properties of the pressure waves are utilized. In the former approach, i.e., the Inverse Transient Analysis (Liggett and Chen, 1994), the governing equations are integrated in the time domain (e.g., Covas and Ramos, 2010) or converted into the frequency domain after having linearized the friction term and the nonlinear boundary conditions (e.g., the ones at the manoeuvre valve and at the leak) to reduce the needed amount of computer time (Covas et al., 2005; Ferrante and Brunone, 2003a; Lee et al., 2005a, b, 2006; Mpesha et al., 2001; Wang et al., 2002). In the latter approach, the characteristics of the possible leaks are inferred directly from transient data - in most cases pressure traces - by measuring the arrival time and the entity of pressure waves at the measurement sections, particularly those reflected by the leaks (Brunone, 1999; Brunone and Ferrante, 2001; Covas and Ramos, 2010; Ferrante and Brunone, 2003b; Ferrante et al., 2009a; Jönsson, 2001; Jönsson and Larson, 1992). A detailed literature review is presented in Colombo et al. (2009).

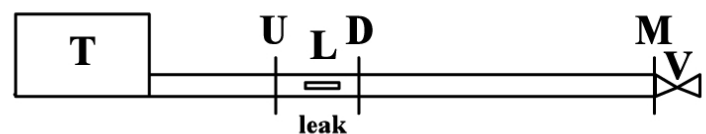

Figure 2. Sketch of the experimental setup $(\mathrm{T}=$ supply tank, $\mathrm{U}=$ section upstream of the leak, $\mathrm{L}=$ leak device, $\mathrm{D}=$ section downstream of the leak, $\mathrm{M}=$ section immediately upstream of the manoeuvre valve, $\mathrm{V}=$ manoeuvre valve).

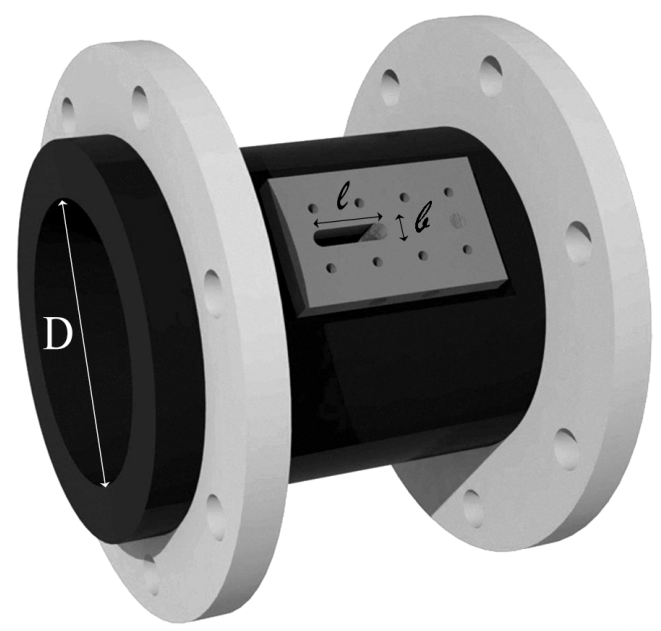

Figure 3. Device used to simulate leaks.

In the present paper, attention is focused on the numerical simulation of transients in a viscoelastic single pipe with external flow, i.e., a leak - hereafter referred to as damaged pipe.

Precisely, the interaction between a pressure wave and different leaks in a plastic pipe is examined during the first phases of the transients. In the first part, laboratory experiments are discussed by pointing out the effect of a leak; in the second part the results of different 1-D numerical models are compared.

\section{Experimental setup}

Experimental tests have been carried out at the Water Engineering Laboratory (WEL) of the University of Perugia, Italy. The experimental setup (Fig. 2) comprises a high density polyethylene (HDPE) pipe with $L=166.28 \mathrm{~m}$, internal diameter $D=93.3 \mathrm{~mm}$, nominal diameter DN110, and wall thickness $e=8.1 \mathrm{~mm}$. This pipe connects the upstream tank to the downstream manoeuvre valve - ball valve DN50 - that discharges in the air.

To investigate the effect of a leak discharging into the atmosphere on the pressure signal, a new device (Fig. 3) with an orifice at its wall is installed at a distance $L^{\prime}=105.44 \mathrm{~m}$ from the manoeuvre valve. With respect to the previous laboratory arrangement (Brunone and Ferrante, 2001; Ferrante and Brunone, 2003b; Ferrante el al., 2009a, b) the new 
Table 1. Geometrical characteristics of leaks used in tests.

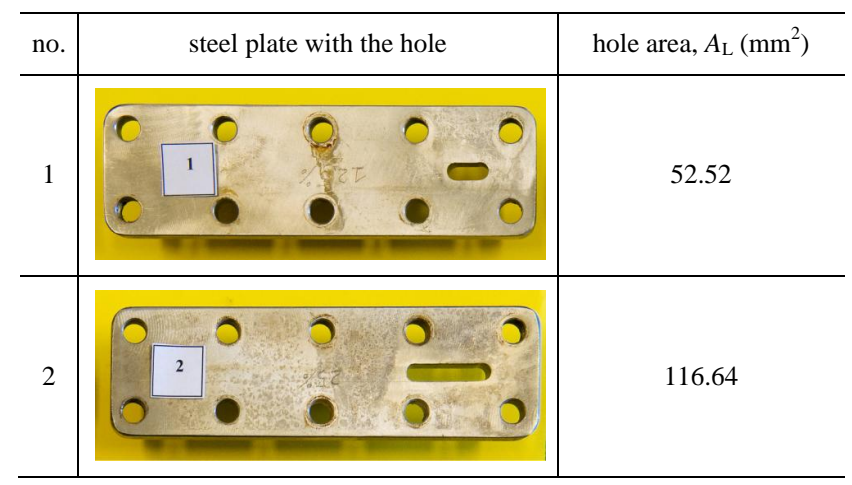

device allows to simulate rectangular leaks of different size by changing the steel plate with the orifice (Table 1 ).

Pressure signal is measured with a frequency acquisition of $1024 \mathrm{~Hz}$ at four sections: section $\mathrm{M}$, immediately upstream of the manoeuvre valve, sections $\mathrm{D}$ and $\mathrm{U}$, placed downstream of the leak (at a distance $s_{\mathrm{D}}=97.50 \mathrm{~m}$ from the end valve) and upstream of the leak $\left(s_{\mathrm{U}}=138.50 \mathrm{~m}\right)$, respectively, and at the supply tank (Fig. 1). Piezoresistive transducers with a full scale of $3.5,7$ or 10 bar, depending on the pressure maximum value during the transient test, are used. The steady-state discharge at the end valve, $Q_{0}$, is measured by means of a magnetic flow meter.

\section{Experimental pressure signals}

Figures 4 and 5 show pressure signals, $H$, measured at section $\mathrm{M}$ in the damaged pipe with the leak no. 1 and no. 2, respectively. During tests, different values of $Q_{0}$, and then of $\Delta H_{\mathrm{AJ}}$, have been considered.

According to literature (e.g., Brunone and Ferrante, 2001; Covas and Ramos, 2010), for a given leak, the larger $\Delta H_{\mathrm{AJ}}$, the larger the pressure wave reflected by the leak.

In Fig. 6 the pressure signals in the single pipe and damaged pipes (with the leaks no. 1 and no. 2) for about the same $Q_{0}\left(\sim 3 \mathrm{~L} \mathrm{~s}^{-1}\right)$, are compared. It can be noted the larger damping occurring in the damaged pipe, as well as that the larger the leak, the larger such a damping (Collins et al., 2012; Colombo et al., 2009).

\section{1-D numerical models}

According to literature (Covas et al., 2004, 2005; Franke and Seyler, 1983; Ghilardi and Paoletti, 1986; Meniconi et al., 2012a, b; Soares et al., 2008), the complete 1-D numerical model to simulate transients in pressurized viscoelastic pipes is based on the continuity equation:

$\frac{\partial H}{\partial t}+\frac{\left(a_{\mathrm{i}}\right)^{2}}{g A} \frac{\partial Q}{\partial s}+\frac{2\left(a_{\mathrm{i}}\right)^{2}}{g} \frac{\mathrm{d} \epsilon_{\mathrm{r}}}{\mathrm{d} t}=0$

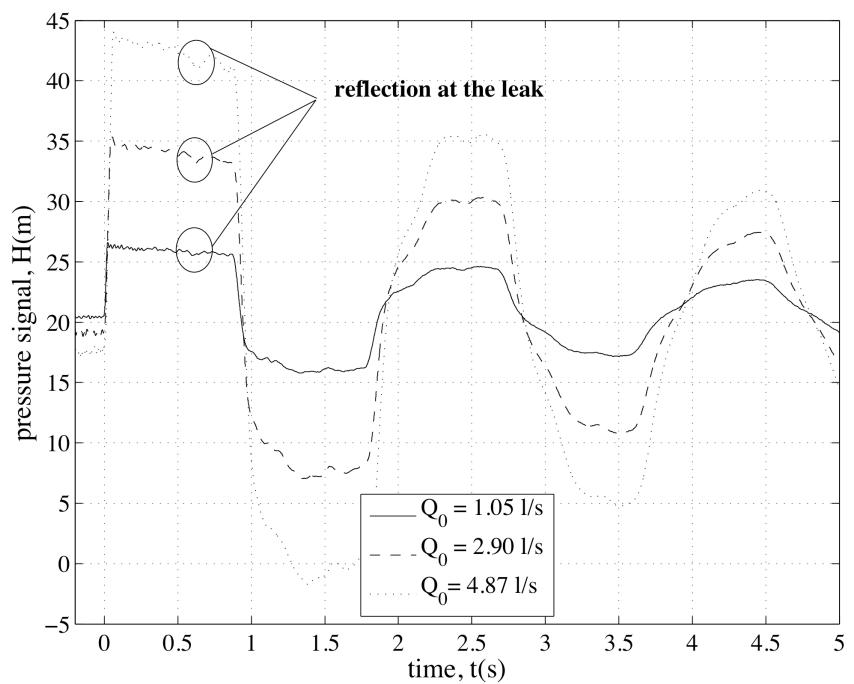

Figure 4. Damaged pipe with leak no. 1 (Table 1): pressure signal at section M for different values of the discharge at the end valve, $Q_{0}$.

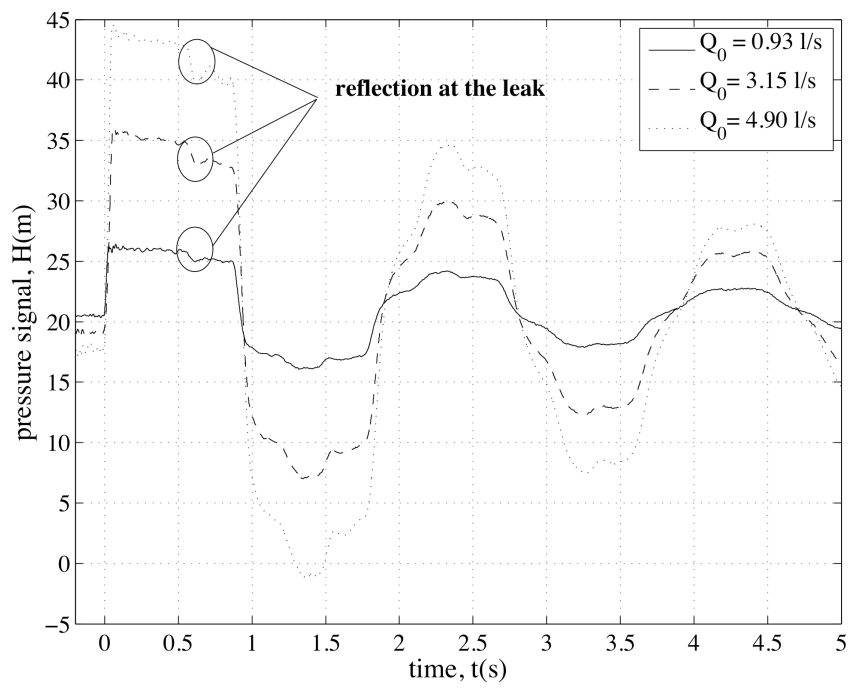

Figure 5. Damaged pipe with leak no. 2 (Table 1): pressure signal at section $\mathrm{M}$ for different values of the discharge at the end valve, $Q_{0}$.

and the momentum equation:

$\frac{\partial H}{\partial s}+\frac{Q}{g A^{2}} \frac{\partial Q}{\partial s}+\frac{1}{g A} \frac{\partial Q}{\partial t}+J=0$,

with $s=$ axial co-ordinate, $J=$ total friction term, and $\varepsilon_{\mathrm{r}}=$ retarded strain. More details on the model and the calibration procedure are reported in Meniconi et al. (2011, 2012a, b). It is worthy of noting that $J$ is regarded as the sum of two components. That is,

$J=J_{\mathrm{s}}+J_{\mathrm{u}}$,

where $J_{\mathrm{s}}$ is the quasi steady-state value based on the instantaneous mean flow velocity, and $J_{\mathrm{u}}$, the additional term 


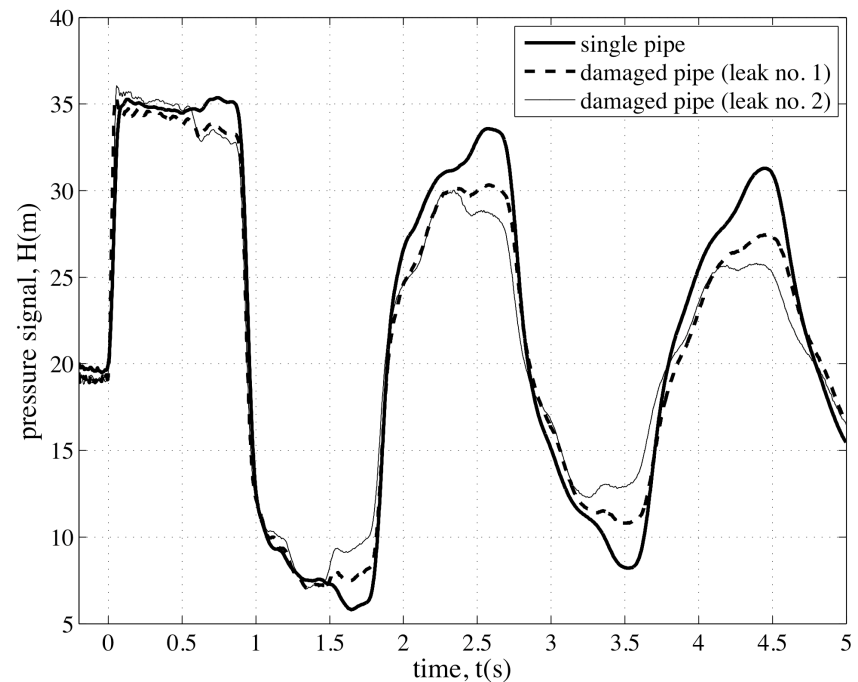

Figure 6. Pressure signal at section $M$ for approximately the same value of the discharge at the end valve, $Q_{0}\left(\cong 3 \mathrm{~L} \mathrm{~s}^{-1}\right)$ in the case of: single pipe, damaged pipe with leak no. 1 and 2 , respectively.

due to unsteadiness (Vardy and Brown, 2003, 2004; Ghidaoui et al., 2005), is evaluated within an instantaneous acceleration-based model by means of the following relationship (Brunone et al., 1991, 1995; Bergant et al., 2001; Pezzinga, 2000):

$J_{\mathrm{u}}=\frac{k_{\mathrm{d}}}{2 g A}\left(\frac{\partial Q}{\partial t}+a^{\mathrm{i}} \operatorname{sign}(Q)\left|\frac{\partial Q}{\partial s}\right|\right)$,

in which $k_{\mathrm{d}}=$ decay coefficient and $\operatorname{sign}(Q)=(+1$ for $Q \geq 0$ or -1 for $Q<0$ ).

Such a complete model can be simplified by neglecting:

1. the unsteady friction $\left(J_{\mathrm{u}}=0\right)$;

2. the unsteady friction and the viscoelasticity $\left(J_{\mathrm{u}}=0\right.$ and $\left.\varepsilon_{\mathrm{r}}=0\right)$;

3. the friction term and the viscoelasticity $(J=0$ and $\left.\varepsilon_{\mathrm{r}}=0\right)$.

The simplified model no. 1 takes into account the predominant effect of viscoelasticity (Duan et al., 2010; Meniconi et al., 2012a, b). The simplified model no. 2 coincides with the steady-state approach for transients in elastic pipes; whereas the last one derives from the classical Allievi-Joukowski theory.

In all models the boundary condition at the leak is given by the Torricelli equation:

$Q_{\mathrm{L}}=C_{\mathrm{L}} A_{\mathrm{L}} \sqrt{2 g\left(H_{\mathrm{L}}-z_{\mathrm{L}}\right)}$,

where $C=$ discharge coefficient, and $z=$ elevation, with the subscript $\mathrm{L}$ referring quantities to the leak.

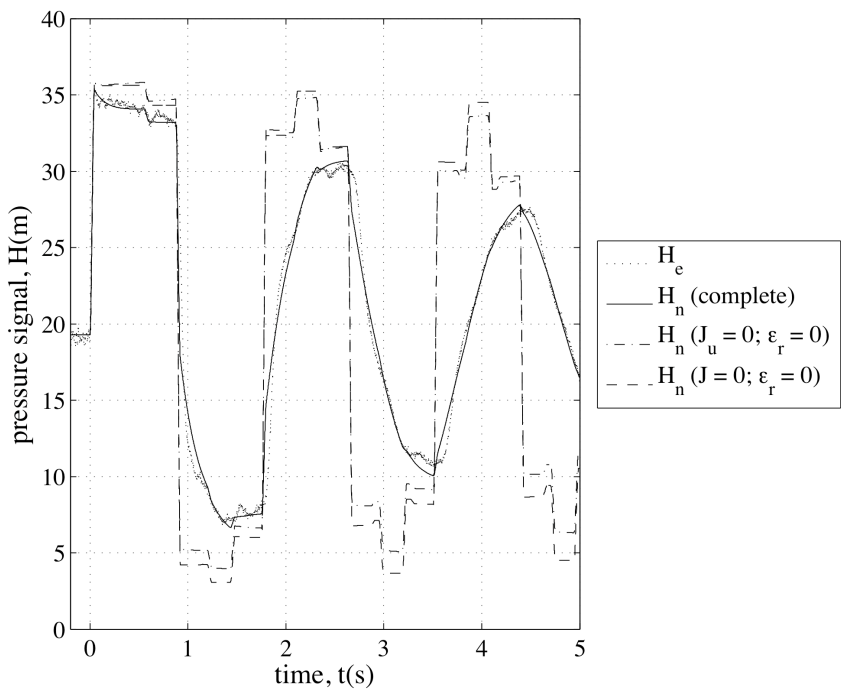

Figure 7. Damaged pipe with leak no. $1\left(Q_{0}=2.90 \mathrm{~L} \mathrm{~s}^{-1}\right)$ : experimental pressure signal at section $\mathrm{M}$ vs. numerical model simulations.

\section{Numerical experiments for a damaged pipe}

Figures 7 and 8 show the comparison between experimental pressure signal, $H_{\mathrm{e}}$, and the numerical simulations, $H_{\mathrm{n}}$, given by the models described in Sect. 4 within the Method of Characteristics (Wylie and Streeter, 1993).

As for the single pipe (Fig. 1), when the simplified models in which the viscoelasticity is neglected are used - i.e., models no. 2 and no. 3 - the main characteristics of the experimental traces are not captured: nor the damping, nor the rounding. With regard to the pressure waves reflected by the leak, only the one occurring during the first characteristic time of the pipe is quite well simulated. On the contrary, the results given by the simplified model no. 1 (not reported in Figs. 7 and 8) are almost indistinguishable from those of the complete model. This confirms the predominance in plastic pipes of viscoelasticity with respect to unsteady friction also for a damaged pipe. A quantitative measure of such behaviours is given in Fig. 9, where, with regard to the first $5 \mathrm{~s}$ of the transient, the determination coefficient $R^{2}-$ denoting the strength of the association between $H_{\mathrm{e}}$ and $H_{\mathrm{n}}$ is reported. For leak no. $1, R^{2}$ assumes the same maximum value $(=0.984)$ for the complete and simplified model no. 1 $\left(J_{\mathrm{u}}=0\right)$. This means that the $98.84 \%$ of the total variation in $H_{\mathrm{e}}$ can be explained by the linear relationship between $H_{\mathrm{e}}$ and $H_{\mathrm{n}}$. The other $1.17 \%$ of the total variation in $H_{\mathrm{e}}$ remains unexplained by the numerical models. The quality of the numerical simulation deteriorates when simplified models no. $2\left(J_{\mathrm{u}}=0\right.$ and $\left.\varepsilon_{\mathrm{r}}=0\right)$ and no. $3\left(J=0\right.$ and $\left.\varepsilon_{\mathrm{r}}=0\right)$ are used. Particularly, for the simplified model no. $2, R^{2}$ breaks down to 0.498 , whereas it becomes 0.475 for the simplified model no. 3. $R^{2}$ exhibits almost the same behaviour for the damaged pipe with leak no. 2 . 


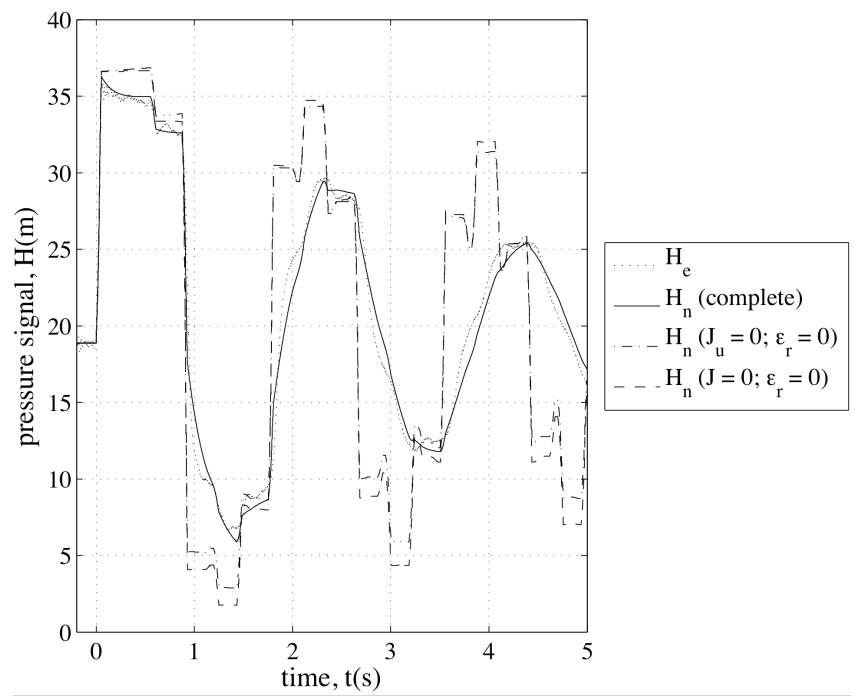

Figure 8. Damaged pipe with leak no. $2\left(Q_{0}=3.15 \mathrm{~L} \mathrm{~s}^{-1}\right)$ : experimental pressure signal at section $\mathrm{M}$ vs. numerical model simulations.

\section{Conclusions}

This paper can be included in the research activity focused on the analysis of the role that unsteady friction and viscoelasticity play in the numerical simulation of transients in plastic pipes. In fact, up to few years ago there was no clear delineation between when and when not include such effects in transient flow numerical models not even for the simplest case of the constant diameter pipe (single pipe). In recent contributions (Duan et al., 2010; Meniconi et al., 2012a, b) such a benchmarking analysis has been executed for the cases of a single pipe, a pipe with a partially closed in-line valve, and a pipe with cross-section changes in series. The important case of a pipe with an external flow due to a leak deserved less attention.

In the first part of this paper the results of tests executed at the Water Engineering Laboratory (WEL) of the University of Perugia, Italy, with a more flexible device to simulate leaks, are discussed. Precisely, it is pointed out the effect of the leak on the pressure signal both in terms of the reflected pressure wave and the damping of the extreme values of the pressure.

In the second part, different numerical models are presented: the complete model, that takes into account both unsteady friction and viscoelasticity, and three simplified models in which the unsteady friction (model no. 1), both the unsteady friction and viscoelasticity (model no. 2), the friction term and the viscoelasticity (model no. 3) are neglected, respectively.

By comparing experimental and numerical results, it is demonstrated the crucial role played by the viscoelasticity with respect to unsteady friction also in the considered case of a plastic pipe with a leak. From a quantitative point of

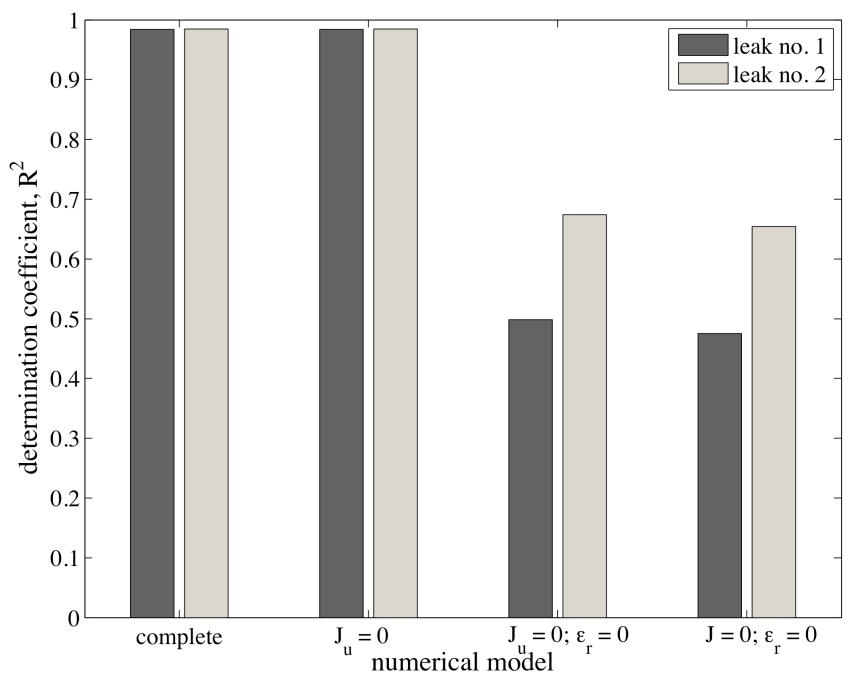

Figure 9. Determination coefficient of the different numerical models in the case of a damaged pipe, with the leak no. 1 (dark grey) and no. 2 (light gray).

view, such a behaviour of numerical models is pointed out by considering the value of the determination coefficient $R^{2}$, which denotes the strength of the association between the numerical and experimental pressure traces during a specified period of time.

Acknowledgements. This research has been supported by Fondazione Cassa Risparmio Perugia under the Project "Leaks and blockages detection techniques for reducing energy and natural resources wastage". The support of A. Cirimbilli, C. Del Principe and A. Adorisio in the laboratory activity is highly appreciated.

Edited by: R. Farmani

\section{References}

Adamkowski A. and Lewandowski, M.: Experimental examination of unsteady friction models for transient pipe flow simulation, J. Fluid. Eng., 128, 1351-1363, 2006.

Bergant, A., Simpson, A., and Vitkovsky, J.: Developments in unsteady pipe flow friction modelling, J. Hydraul. Res., 39, 249257, 2001.

Brunone, B.: A transient test-based technique for leak detection in outfall pipes, J. Water Res. Pl., 125, 302-306, 1999.

Brunone, B. and Berni, A.: Wall shear stress in transient turbulent pipe flow by local velocity measurement, J. Hydraul. Eng., 136, 716-726, 2010.

Brunone, B. and Ferrante, M.: Detecting leaks in pressurised pipes by means of transients, J. Hydraul. Res., 39, 539-547, 2001.

Brunone, B., Golia, U. M., and Greco, M.: Some remarks on the momentum equation for fast transients, in: Proc. Int. Meeting on "Hydraulic Transients and Water Column Separation", edited by: Cabrera, E. and Fanelli, M., 201-209, 1991. 
Brunone, B., Golia, U. M., and Greco, M.: Effects of twodimensionality on pipe transients modeling, J. Hydraul. Eng., 121, 906-912, 1995.

Collins, R. P., Boxall, J. B., Karney, B. W., Brunone, B., and Meniconi, S.: How severe can transients be after a sudden depressurization?, J. Am. Water Works Ass., 104, E243-E251, 2012.

Colombo, A. F., Lee, P., and Karney, B. W.: A selective literature review of transient-based leak detection methods, J. HydroEnvironment Res., 2, 212-227, 2009.

Covas, D. and Ramos, H.: Case studies of leak detection and location in water pipe systems by inverse transient analysis, J. Water Res. Pl., 136, 248-257, 2010.

Covas, D., Stoianov, I., Mano, J., Ramos, H., Graham, N., and Maksimovic, C.: The dynamic effect of pipe-wall viscoelasticity in hydraulic transients. Part I - Experimental analysis and creep characterization, J. Hydraul. Res., 42, 516-530, 2004.

Covas, D., Stoianov, I., Mano, J., Ramos, H., Graham, N., and Maksimovic, C.: The dynamic effect of pipe-wall viscoelasticity in hydraulic transients. Part II - Model development, calibration and verification, J. Hydraul. Res., 43, 56-70, 2005.

Duan, H., Ghidaoui, M., Lee, P. J., and Tung, Y. K.: Unsteady friction and visco-elasticity in pipe fluid transients, J. Hydraul. Res., 48, 354-362, 2010.

Ferrante, M. and Brunone, B.: Pipe system diagnosis and leak detection by unsteady-state tests. 1 Harmonic analysis, Adv. Water Res., 26, 95-105, 2003a.

Ferrante, M. and Brunone, B.: Pipe system diagnosis and leak detection by unsteady-state tests. 2 Wavelet analysis, Adv. Water Res., 26, 107-116, 2003b.

Ferrante, M., Brunone, B., and Meniconi, S.: Leak detection in branched pipe systems coupling wavelet analysis and a lagrangian model, J. Water Supply Res. T., 58, 95-106, 2009a.

Ferrante, M., Brunone, B., and Meniconi, S.: Leak-edge detection, J. Hydraul. Res., 47, 233-241, 2009b.

Ferrante, M., Massari, C., Brunone, B., and Meniconi, S.: Experimental evidence of hysteresis in the head-discharge relationship for a leak in a polyethylene pipe, J. Hydraul. Eng., 137, 775-781, 2011.

Franke, P. and Seyler, F.: Computation of unsteady pipe flow with respect to visco-elastic material properties, J. Hydraul. Res., 21, 345-353, 1983.

Ghidaoui, M. S., Zhao, M., McInnis, D. A., and Axworthy, D. H.: A review of water hammer theory and practice, Appl. Mech. Rev., 58, 49-76, 2005.

Ghilardi, P. and Paoletti, A.: Additional visco-elastic pipes as pressure surges suppressors, in: Proc. 5th Int. Conf. on "Pressure Surges", 113-121, 1986.

Jönsson, L.: Experimental studies of leak detection using hydraulic transients, in: Proc. 29th IAHR Congress, 559-565, 2001.

Jönsson, L. and Larson, M.: Leak detection through hydraulic transient analysis, in: Proc. Int. Conf. on "Pipeline Systems", edited by: Coulbeck, B. and Evans, E., Kluwer Academic Publishers, 273-286, 1992.
Lee, P. J., Vitkovsky, J. P., Simpson, A. R., Lambert, M. F., and Liggett, J.: Frequency domain analysis for detecting pipelines leaks, J. Hydraul. Eng., 131, 596-604, 2005a.

Lee, P. J., Vitkovsky, J. P., Lambert, M. F., Simpson, A. R., and Liggett, J.: Leak location using the pattern of the frequency response diagram in pipelines: a numerical study, J. Sound Vib., 284, 1051-1073, $2005 b$.

Lee, P. J., Lambert, M., Simpson, A., and Vitkovsky, J. P.: Experimental verification of the frequency response method of leak detection, J. Hydraul. Res., 44, 451-468, 2006.

Liggett, J. A. and Chen, L.-C.: Inverse transient analysis in pipe networks, J. Hydraul. Eng., 120, 934-955, 1994.

Meniconi, S., Brunone, B., Ferrante, M., and Massari, C.: Long period analysis of transient pressure signals for in-line valve checkin, in: Proc. 11th Int. Conf. on "Computing and Control for the Water Industry - CCWI2011 Urban Water in Management: Challanges and Opportunities", Exeter, edited by: Savic, D. A., Kapelan, Z., and Butler, D., 3, 787-792, 2011.

Meniconi, S., Brunone, B., Ferrante, M., and Massari, C.: Transient hydrodynamics of in-line valves in viscoelastic pressurized pipes: long-period analysis, Exp. Fluids, 53, 265-275, 2012a.

Meniconi, S., Brunone, B., and Ferrante, M.: Water hammer pressure waves at cross-section changes in series in viscoelastic pipes, J. Fluid. Struct., 33, 44-58, doi:10.1016/j.jfluidstructs.2012.05.007, 2012b.

Mpesha, W., Gassman, S. L., and Chaudhry, M. H.: Leak detection in pipes by frequency response method, J. Hydraul. Eng., 127, 134-147, 2001.

Pezzinga, G.: Evaluation of unsteady flow resistances by quasi-2D or 1D models, J. Hydraul. Eng., 126, 778-785, 2000.

Pezzinga, G.: Local balance unsteady friction model, J. Hydraul. Eng., 135, 45-56, 2009.

Soares, A. K., Covas, D., and Reis, L. F. R.: Analysis of PVC pipewall viscoelasticity during water hammer, J. Hydraul. Eng., 134, 1389-1395, 2008.

Storli, P. T. and Nielsen, T. K.: Transient friction in pressurized pipes. II: Two-coefficient instantaneous acceleration-based model, J. Hydraul. Eng., 137, 679-695, 2011.

Vardy, A. and Brown, J.: Transient turbulent friction in smooth pipe flows, J. Sound Vib., 259, 1011-1036, 2003.

Vardy, A. and Brown, J.: Transient turbulent friction in fully rough pipe flows, J. Sound Vib., 270, 233-257, 2004.

Wang, X. J., Lambert, M. F., Simpson, A. R., Ligett, J. A., and Vitkovsky, J. P.: Leak detection in pipelines using the damping of fluid transients, J. Hydraul. Eng., 128, 697-711, 2002.

Wylie, E. B. and Streeter, V. L.: Fluid transients in systems, Prentice Hall, Englewood Cliffs, N.J., 1993.

Zielke, W.: Frequency dependent friction in transient pipe flow, J. Basic Eng., 90, 109-115, 1968. 